
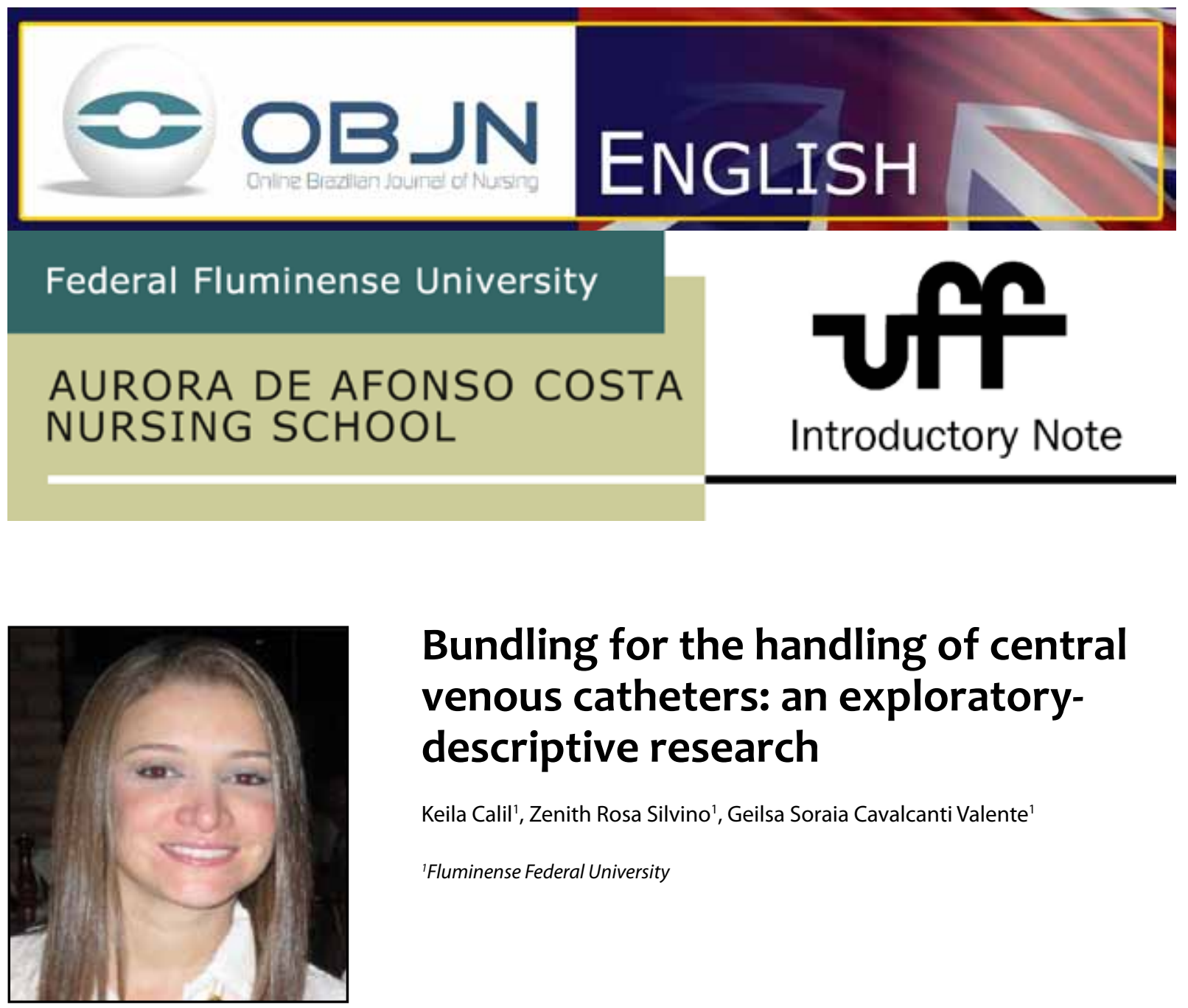

\title{
Bundling for the handling of central venous catheters: an exploratory- descriptive research
}

\author{
Keila Calil' ${ }^{1}$, Zenith Rosa Silvino', Geilsa Soraia Cavalcanti Valente \\ 'Fluminense Federal University
}

\section{ABSTRACT}

This is a dissertation project from the Professional Masters Program in Assisting Nursing. Aims: To identify, in the literature, the scientific evidence with regard to preventing Primary Bloodstream Infection (BSI) in patients using a Central Venous Catheter (CVC); to elaborate on standards and criteria based on the scientific evidence to evaluate the nursing actions with regard to the prevention of such infections and; to build a bundle to handle CVC in order to prevent BSI.

Method: This is an exploratory-descriptive research, with a quantitative and qualitative approach, dealing with the scientific evidence found in Brazil and abroad.

Descriptors: Catheter-Related Infections; Hospital Infection Control Program; Nursing; Process Assessment (Health Care). 


\section{PROBLEM SITUATION AND ITS MEANING}

The object of this study is the search for scientific evidence of ways in which to prevent Primary Bloodstream Infection (BSI) in patients using a Central Venous Catheter (CVC).

$\mathrm{BSI}$ represents one of the main concerns in healthcare, with a consequent impact in morbidity and mortality of patients, especially in terms of those who, because of the seriousness of their disease, need a CVC ${ }^{(1)}$.

International data show that, in Intensive Care Units (ICU), $48 \%$ of patients need a CVC, a total of 15 million catheters/day, per year. The density of occurrence of infection is 5.3 catheterrelated infections, for each 1,000 catheters/day ${ }^{(2)}$.

The mortality attributed to such infections is about $18 \%$, and therefore there are 14 thousand deaths per year due to infections related to the use of catheters. However, there are reports that mention 28 thousand deaths per year ${ }^{(2)}$.

There is a need to explain that infections in the bloodstream originating in a hospital extend the hospitalization period by an average of seven days or more, and the costs related to these events are estimated at between US\$ 3,700 to US\$29,000 per event ${ }^{(2)}$.

Based on the presented facts, we can affirm that the healthcare service is not as safe as expected by users and their relatives. This fact is demonstrated in the publication of the book 'To Err is Human: Building a Safer Health System' ('Errar é Humano: construindo um sistema de saúde seguro', in Portuguese), which called the attention of people in the United States and around the world, to 'patient safety'.

It is known that nursing teams have a great deal to contribute to revising or to ameliorating this situation, once the actions directed to the prevention of these infections are put into place.

In order to guarantee the safety of the patient, by paying extra attention to the reduction of the incidence and gravity of healthcarerelated infections (IrAS, in Portuguese), the Brazilian National Agency of Sanitary Surveillance (ANVISA, in Portuguese) has developed directives and standards and, in 2010, established a national target of reducing to $30 \%$, the incidence of $\mathrm{BSI}$ in patients using $\mathrm{CVC} \mathrm{C}^{(3)}$.

In this context, ANVISA determines that each health facility must revaluate the assisting practices provided to the patients, and they also need to implement a program to reduce the incidence of infections depending on the facility's characteristics, based on the use of bundles ${ }^{(3)}$.

A bundle is a strategy of intervention based on simple and effective measures which enable healthcare facilities to rethink the assistance provided to their patients using CVC, providing quality to the practice of nursing care.

A bundle is, then, a set of good practices (three to six processes) which are scientifically determined, and refer to a certain pathology. Individually, they result in an improvement in healthcare and, when implemented together, present an even better result. These practices are grouped together and presented to teams involved in caring. This team will proceed to operate in terms of all the criteria contained in the bundle ${ }^{(2)}$.

From the point of view of epidemiological vigilance in terms of hospital infections, it is possible to identify and define the cases of BSI in patients using CVC, which have led to the need to evaluate the work processes related to caring, with the objective of improving and/or redirecting the quality of healthcare service provided. Within this context, the following questions arose: what are the recommendations established in terms of the Brazilian and international directives to prevent BSI in patients using CVC? What are the standards and criteria with which to evaluate the execution of nursing actions to 
prevent BSI in patients using CVC through the use of a bundle?

Thus, this research has a general objective to build a bundle to handle CVC, in order to prevent BSI. As specific objectives, we have that of identifying, from the scientific literature, the scientific evidence that exists with regard to the prevention of BSI in patients using CVC. In addition, we wish to develop standards and criteria from the scientific evidence to evaluate nursing actions in order to prevent these infections.

\section{METHOD}

This is an exploratory-descriptive research, with a qualitative and qualitative approach; this study aims to find scientific evidence in the last five years in databanks in Brazil and abroad, about the prevention of BSI in patients using CVC. In this way it will be possible to establish the standards and the criteria needed to elaborate the bundle, with regard to the professional context of the area of work of one of the authors.

In the second semester of 2013, the search will be done in the Virtual Health Library (VHL) and in the US National Library of Medicine/ National Institutes of Health (PubMed), using the following descriptors: Infections related to Catheter; Hospital Infection Control Program; Nursing; Evaluation of Processes (Healthcare). After the selection of data, the findings will be organized and analyzed in terms of the quantity of scientific publications produced in Brazil and in the world. The content will then be discussed based on thematic categories.

Because this involves public domain information, and because this study does not involve human beings during the collection of data, there is no need to submit this research for evaluation by the Ethics in Research Committee, according to the parameters established by the Brazilian National Health Council.

\section{REFERENCES}

1. Andrade MR, Silva HG, Oliveira BGRB, Cruz ICF. Risk of infection in central venous catheter: review study to nursing care. Online braz j nurs [Internet]. 2010 [cited 2013 Jan 12]; 9 (2): [about 4 p.]. Available from: http://www. objnursing.uff.br/index.php/nursing/article/ view/j.1676-4285.2010.3109/700

2. Institute for Healthcare Improvement. Getting Started Kit: Prevent Central Line Infections How-to Guide. Cambridge: Institute for Healthcare Improvement; 2012.

3. Agência Nacional de Vigilância Sanitária (Brasil), Unidade de Investigação e Prevenção das Infecções e dos Eventos Adversos. Corrente Sanguínea: Critérios Nacionais de Infecções Relacionadas à Assistência à Saúde. Brasília: Anvisa; 2009.

\section{Information of the Project}

Dissertation project of the Professional Masters Program in Assisting Nursing at Fluminense Federal University, Brazil.

Tutor: Zenith Rosa Silvino

Cotutor: Geilsa Soraia Cavalcanti Valente.

Financial Support to the Research: Regional Nursing Council (COREN/RJ).

Received: $26 / 08 / 2013$

Revised: 02/09/2013

Approved: 04/09/2013 